\title{
Culture Restrictions as a Trigger to the Society Development: History and Modernity
}

\begin{abstract}
Submitted 15/03/19, 1 st revision 11/05/19, $2^{\text {nd }}$ revision 28/05/19, accepted 05/06/19
Gushchina L.V. ${ }^{1}$, Kislitsyna N.N. ${ }^{2}$, Agapova E.A. ${ }^{3}$, Izotova N.V. ${ }^{4}$ Abstract:

Purpose: The main aim of this paper is to analyze cultural restrictions, taboos and bans inherent in society at any stage of its existence and their role in spiritual and intellectual transformations.

Design/Methodology/Approach: For the purpose of investigating and classifying numerous cultural alternations which acted as a trigger to spiritual and intellectual transformations challenging a nation's cognitive potential it seems necessary to fulfill three conditions described in the text.

Findings: The authors emphasized the fact that culture consists of several layers: spiritual, intellectual and technical. With the degradation of any of these layers culture suffers. The authors formulated the idea that such restrictions occuring in the society as censorship, for example, are likely to be relevant as long as the society itself exists and more over they present a rather stable element of a society.

Practical Implications: The results may be implemented into sociocultural practices for better understanding of some main laws and cornerstones forming cultural foundations. Originality/Value: The main contribution of this study lies in the emphasis of the role of culture, especially its spiritual layer represented by religion, morale, philosophy, literature, art, history, in quite natural and unavoidable technological development and progresses.
\end{abstract}

Keywords: Cultural restrictions, censorship, trigger, spiritual and intellectual layers.

JEL codes: D90, P20, Z10.

Paper Type: Research article in Special Issue dedicated to Russian Economy.

Section 6: Linguistics.

\footnotetext{
${ }^{I}$ PhD in Philology, Associate Professor of the Department of English Theory and Practice, Institute of Philology, Journalism and Cross-Cultural Communication, Southern Federal University, Rostov-onDon, Igushchina@sfedu.ru

${ }^{2}$ Ph.D. in Philology, Associate Professor, Head of the Department of Foreign Languages №1, Institute of Foreign Philology, Taurida Academy, Crimean Federal University by V.I. Vernadski, nkislitsyn@ rambler.ru

${ }^{3}$ D.Sc in Philosophy, Associate Professor, Head of the Department of Social Philosophy, Institute of Philosophy and Socio-political Sciences, Southern Federal University, Rostov-on-Don, Russia, eagapova@sfedu.ru Scopus authid 57204128108

${ }^{4}$ D.Sc in Philology, Professor of the Department of the Russian Language, Institute of Philology, Journalism and Cross-Cultural Communication, Southern Federal University, Rostov-on-Don, nvizotova@sfedu.ru
} 


\section{Introduction}

In the $21^{\text {st }}$ century - the century of the conflict of values and information wars conquering a foreign state does not necessarily require taking over its territory: the mission can rather efficiently be accomplished through civilized manipulation of its residents designed to contaminate and distort public consciousness and cognitive potential. These processes manifest themselves most prominently in the realm of culture. As Estonian culture expert Yuri Lotman (2000) rightly noted, culture begins with exclusion, self-restraint and self-control - the things that formalize the core of personal responsibility. Culture operates through its different layers, of which the core layers are considered to be the spiritual, intellectual and technical ones. The spiritual layer of culture is represented by religion, morale, philosophy, literature, art, history; the intellectual layer is rendered through the science; the technical layer is mirrored in crafts, engineering and technology, whereby an individual interacts with the society and the nature. The most hazardous scenario is the one involving the decay of culture's spiritual layer, which is essential to its evolution: if the spiritual layer is at risk, the culture might as well end up replaced by counter-culture.

The present paper aims to analyze cultural alternations, especially numerous taboos and bans occurring within a society at different stages of its development which acted as a trigger to spiritual and intellectual transformations challenging a nation's cognitive potential leading to technological progress.

All the history of culture is full of different bans and restraints. Culture starts out as a restraint, a taboo which yet needs to be disguised. A human being instinctively requires a sense of direction: we do not always cognize and act as we should, yet we reflexively know how things should be done. The rules that traditional cultures pass on a priori through generations will call for rational elucidation in modern societies. The world has changed, and the changes are orchestrated by the European civilization driven by the ideas of technological advancement and benefit. Obviously, technological development is essential to our evolution: as the mankind forges ahead, this kind of progress appears natural and unavoidable. But one should not underestimate the role of culture in promoting this process.

\section{Literature Review}

Proceeding from the diachronic analysis, the most ancient period in the history of mankind when formation of the bans as a way of regulation in culture began, is primitive society. The social system of primitive people owing to backwardness of productive forces caused, first of all, by extremely low equipment was characterized by joint work, an ownership in common on means of production, leveling distribution of products of consumption and equality of people in public life. The data of the life of primitive people are rather poor and sketchy, however even the available researches made in this area grant to us the right to claim that at the beginning of human life different prototypes of modern socio-political institutes 
begin to be formed. As the researcher of history of primitive society Yu.V. Knyshenko (1973) noticed: "Past has the attractive force because in the past germs of the present are concealed and future seeds ripen".

Let us note that rudiments of various bans and restrictions, in their modern image were formed at an initial stage of existence of human society and represented the first social institutes which included the system of the bans on certain actions - a taboo. Violation of the bans was supported with real punishments, frequently even the death. Fraser (1913) insisted on the fact that the taboo existed in all societies. According to Durkheim (1968), social consequences of observance of a taboo is association of social group out of ordinary rituals and sensual manifestations. The taboo is a symbol of membership in a certain group.

Freud (1989) considered a taboo as ethical standard, the first in the history of mankind. Radkliff-Brown (2014) considered a taboo timeless ethical standard regulating behavior of members of society according to the norms and values accepted in it. However, the tabooing at an early stage of formation of public groups had rather intuitive character, and their purpose was to survive and keep integrity of community. Dissent as such during the "pre-state" period did not exist because of the social order.

At the present stage of development of a civilization such phenomenon as censorship embodied in social institutes, remaining in cultures with the totalitarian form of government and also in the cultures of post-figurative type is of great interest (Goryaeva, 1998; Agapova and Firsova, 2017; Severina, Agapova and Milkevich 2018).

Fon Hayek (2001) explains the reasons of this phenomenon as follows: “... in order that people recklessly supported common cause, they have to be convinced, as the purpose, and means are chosen correctly. Therefore the official belief to which it is necessary to acquaint everybody will include interpretation of all the facts concerning the plan, and any criticism or doubt will be resolutely suppressed because they can weaken unanimity".

Culture restrictions have their strong influence on the adoption of a universal codes of ethics in different spheres of life.

\section{Research Methods}

The methodological basis of the research is determined by the systemic and evolutionary approaches chosen, thanks to their application making it possible to create and analyze not only a static but also a dynamic model of culture through a consecutive theoretical reproduction of its development. Such research methods as structuralist, reflexive, of the phenomenological analysis serve to identify the factors of the social forces defining the culture transformation. 


\section{Results}

It is rather significant, in our opinion, to emphasize that in a fairly homogeneous society, there was no need to identify and punish dissent, but need of the bans and restrictions connected with regulation of biological life of society existed and was expressed in various types of a taboo (religious, marriage and sexual, etc.). Thus, intuitively realizing need of restrictions for viability of society, the person establishes the bans on certain actions and lifestyle which can lead one or another group to decay. Any existing rules, first of all, are the manifestation of the power, and not only power of instincts, environment, circumstances, but social, public power. And at this stage a basis of the power lies in the following - the interests of society tracing its roots back to the system of the social and economic relations and the actions of the people coinciding with the interests of the society are approved by the latter. And the actions which are contrary to the interests of society, are harmful, entail condemnation and punishment by society. These norms are known under the name of a taboo.

Ethnologists have identified these norms from the variety of forms of behavior that existed in primitive societies. The researchers suggested that it was in this form that the most ancient forms of existing human behavioral norms emerged. That is, taboos are prohibitions to commit certain actions, which imply a hidden danger, for society and culture. They are aimed at neutralizing real to life, often menacing death to all community, but still logically not explained threat. Taboo is an inevitable necessity, an axiom, an element of the primary system of social prohibitions, a radical means of initial socialization. The situation changes when "the creative minority" regenerates in an elite, and there is a need to prove the right to power by force of arms and suppression of dissent. This period in the history of mankind is characterized by the emergence of the state, the collapse of the tribal system, the division into classes. As a result, there is a natural need to perpetuate the right of the elite to dominate and not allow the "uncreative minority" to think differently. Thus, the most terrible punishment was established for heresy, to which everything that goes against the ideals of power is counted, and, accordingly, can weaken or destroy power.

One of the first thinkers to realize this problem was Plato (1999). Creating the concept of an ideal state, he relied on the theory of eternal ideas. The perfect state could not exist without the ordered public life necessary to create worthy life of citizens. In the second book of the "Laws", Plato writes that the state is obliged to ensure the existence of an information field, for which the state propaganda is necessary. The philosopher describes the propaganda state system in the form of three "choirs", where the choir acts on the consciousness of society and forms it. Information - according to Plato - should bear a positive start, therefore, everything that violates such harmony should be prohibited, and such prohibitions can be classified as censorship. 
Plato (1994) pays considerable attention to education and comes to the conclusion that censorship, as a form of prohibition, must exist over literature that young people could read from a very young age, and on music that they were allowed to listen to. Mothers and nannies should only tell permitted stories to children. Reading of Homer and Hesiod should not be allowed for a number of reasons: they depict gods that do not always behave decently, young people need to be taught that evil never comes from gods, since God is not the creator of all things, but only good ones. Homer has passages praising rich feasts, as well as passages describing the desires of the gods; such passages discourage moderation. There should be no stories in which bad people are happy and good ones are unhappy: the moral influence of such stories could prove to be the most disastrous for receptive minds. Because of all this, poets should be condemned. Next, Plato talks about the censorship of music. Lydian and Ionic harmonies should be forbidden due to the fact that they express sadness and relax. Only Dorian and Phrygian for courage and moderation should be allowed. Thus, the permissible rhythms should be simple and express courage and harmonious life. Antiquity, in contrast to the earlier "pre-state" stage, develops at a conscious level a system of norms and prohibitions, which are no longer limited only to the preservation of biological existence. Changing the picture of the world and production methods dictates new schemes of social order.

The centuries-long existence of a person in the local information space has made it possible to develop quite effective norms and rules for the behavior of people in this space, to create effective legal, administrative and ethical mechanisms governing the interaction of all elements of society in the information space and ensuring the security of such interaction. History knows many examples of the introduction of administrative, legal and religious bans on the dissemination of information that can shake the foundations on which power in society rests, and the creation of bodies that monitor the implementation of bans and punish them for their violation.

The punishment of Socrates in ancient Greece, the Inquisition in the Middle Ages, the persecution of dissidents, the burning of books and the destruction of unwanted information indicate that the ruling elite has always sought to make the surrounding information space safe, at least for themselves. As a social practice, the prohibition has its roots in deep antiquity, over the course of history, it has repeatedly changed its forms, leaving unchanged the main function - ideological, sometimes moral, control. The change in the forms of prohibitions is natural and associated with the historical development of societies. The ancient civilization with the polis system as a certain stage in the development of society with its own institutions, cultural practices (in various manifestations), as a result of the conquests of Alexander the Great and qualitative changes that occurred due to a change in the sociopolitical situation cannot already exist according to the old laws and use outdated. Society entered a new phase of development, the mighty Roman Empire collapsed in the 5th century, and with it the entire ancient world passed away. In 476, the last Roman emperor Romulus Augustus was overthrown by Odoacrates, the leader of the German troops, and the empire ceased to exist. This was preceded by a long time of 
extinction of the economic and social forces of the state.

Civilization has entered a new stage, the ancient civilization with the wealth of material and spiritual culture was rejected, temples destroyed or transferred to Christian basilicas, books burned. The whole system of moral values, the concepts of good and evil has moved: what was formerly called good was called evil. At the same time, a devastating blow to ancient culture was caused not so much by the barbarians from the outside, as from within by the peoples who inhabited the vast Roman Empire. Antique slave relations did not correspond to the changed world.

In the countries of Western Europe gradually evolved other social relations feudalism. The new social structure demanded a new ideology, the value orientations changed dramatically, and the forms of prohibitions changed with them. Christianity becomes a new social ideology in feudal society, the main function is to destroy heresy and dissent, to assert the authority of the new government, to control information that is contrary to Scripture, and to supervise the correctness in the correspondence of sacred texts. Thus, due to cardinal changes in society and the polar shift of values, the new institution, the Church, is engaged in the formation of bans. Antique and medieval prohibitions differed in form, but not in essence, they performed primarily an ideological function in society. It should be noted that changes in the socio-political structure led to changes in the thinking of people. The theocratic power proclaimed any newness of thought, descended from the devil, and called to keep the purity of faith. The ruling classes influenced the spiritual life of society, seeking to consolidate in his mind the thoughts of submission to fate and the share that fell to him. A medieval person is always a member of a group with which he is closely associated. In other words, medieval society is corporate from top to bottom. The corporation rejects the unconventional behavior of its members, which is at variance with its accepted standard. Violators of regulations and codes are morally condemned, punished, expelled from groups.

It should be mentioned that the basis of medieval prohibitions primarily lies in the fact of departing from the established standard of behavior. All forms of life in a feudal society were subject to the rules, the deviation from which was forbidden and condemned. The traditionalism of social practice of the Middle Ages, dependence on religion gave rise to the universal normative nature of human social behavior. By virtue of this norm, prohibitions acquired the value of a universal and allencompassing regulator of social relations. At first, the clergy carried out observation of them, as free-thinking, spreading in society, began to threaten the authorities, the clergy sought from the secular authorities more stringent measures.

Heretics and their works are burned at the stake. With the advent of the printing press begins, perhaps, the most serious stage, which is characterized by more careful attention to thought from the government. The government releases knowledge in small doses and, following the clergy, repeats the need for a person not to have a lot of knowledge, but faith and obedience. 
After the invention of writing, and especially typography, the dissemination of ideas began to occur through literature, and this is precisely the main reason why, throughout history, the authorities show such attention to thought and try to control and restrain the latter. Lotman (2002) in the article "Culture and Information" makes the following conclusion: "We cannot point to any human collective throughout the centuries-old history of people (if this collective had minimal stability and was not lost, in fact, was already dead!) texts, social behavior carried out by special people or the whole team at a special time to serve a special, cultural function". Culture is a rather complex organism of cognition. This is an area of social, class and historical conflicts. Various social and historical groups, thus fighting for information, tend to monopolize it. At the same time, the means used in achieving monopolization range from taboos and secret texts to censorship itself in its various manifestations.

Analysis of the world history of culture shows that changes in power are the result of changes in the public consciousness. Thus, the basis of social development is the level of awareness by the masses of their position and the level of their claims for freedom and its guarantees. Proceeding from this, we can conclude: the requirements of society are primary, the power is secondary. Awareness of the masses of their needs is determined by ideas that are popular in society.

\section{Discussion}

The sociopolitical situation, the forms and instruments of production change, another ideology is replaced one by another, and as a result, the ways of control over thought change. Even with the complete abolition of censorship as an institution of power, the activity of the latter does not stop. It is simply transformed from an official body of a state into an unwritten body of supervision and control over the intellectual activity of the company. The state, pursuing its goals (thought control), can redeem the media (thus, the information will be refined), restrain the level of literacy and education in general (this is also a type of censorship), apply economic sanctions (quite effective censorship measure to suppress dissent) it is very difficult to prove that these measures in relation to the media have a censorship nature.

Censorship as a phenomenon operates within a society regardless of the formal suppressions introduced to abolish its institutes. A society of hierarchical relations will by all means incorporate censorship in some form or other. At the early stages of its making, in the context of insufficient information flows, censorship emerges as a taboo, which figuratively refers to any prohibition whatsoever whereby its violation is considered a threat to the society. Later on, when religious oeuvre starts to fall back on the tendentious and often vested interests of the priests and the secular authorities, the system of taboo evolves into the fabric of rulemaking that eventually enlaces all aspects of social operation. As information flows and the means of their dissemination gain ground, the institute of censorship becomes established together with the ensuing censorial restrictions. When the new realia associated with the amplification of information flows fail to exercise control, the 
institute of censorship ends up replaced by economic levers, the new technology (including manipulative technology), as well as prohibitions and restrictions diffused throughout the legal system. Yet the express purpose of these practices is to impose constraints, monitor the information and suppress certain types of activity.

Thus, in all its forms and modes of operation, censorship presents a rather stable element of a society. Any reasoning suggesting that the phenomenon of censorship can be eradicated with constitutional law or by phasing the term out of usage will have to be declared utopic.

It is obvious that part of the culture that is usually called spiritual suffers first of all. There is a general spiritual impoverishment and degradation, the dominance of mass culture and, as a result, the loss of national and cultural identity. There is a marginalization of the spheres of spiritual culture, which, in turn, lowers the level of education in society, increases the degree of manipulation of public consciousness and the "controllability" of society. A person in such a society feels that he is part of a crowd (not a collective), but at the same time without feeling the support and feelings of the elbow.

Society turns into an elite and controlled crowd, each member of which is not spiritually connected with the rest. There is no doubt that the causes of negative changes in a post-classical type of society are not only due to the transformation of the institution of censorship, but all processes are interrelated and the rejection of prohibitions is one of the central places in the de-culture of society towards the end of history.

\section{Conclusion}

Taking into consideration everything written above we may state the following:

Culture begins with a ban, with self-restraint, self-control, underlying personal responsibility. The spiritual layer of culture is represented by religion, morality, philosophy, literature, art, history; intellectual - science; technical - craft, technology through which people and society interact with nature. With the degradation of any of the layers, culture as a whole suffers, the erosion of the spiritual core of a culture, without which its development is impossible, is especially dangerous.

A ban or censorship has existed and will always exist. The idea of censorship as a filter and prohibitive mechanism in the interests of one or another ruling elite is likely to be relevant as long as society itself exists, but methods and forms will vary from rigid and official to hidden economic ones. At the same time, the amplitude of such a pendulum depends on the problems that this culture will solve at the moment.

One can formally abandon the prohibitions and control of information flows, but the 
essence of the processes of emasculation of unpopular ideas will not stop, but will enter a new, possibly more sophisticated phase. Thus in all its forms and modes of operation, censorship presents a rather stable element of a society.

\section{References:}

Agapova, E., Firsova, E. 2017. Sociocultural Aspect of Investigation of Censorship. Language, Individual \& Society, 11, https://www.scientific-publications.net/en/openaccess-journals/language-individual-and-society.

Barrainkua, I., Espinosa-Pike, M. 2015. Cultural and Socio-Economic Restrictions for the Adoption of the IESBA Code of Ethics for Professional Accountants in the European Countries. European Research Studies Journal, 1(18), 3-24.

Durkheim, E. 1968. Les formes élémentaires de la vie religieuse. Le système totémique en Australie. Paris, Les Presses universitaires de France, 647.

Frazer, J.G. 1913. Taboo and the Perils of the Soul, 446.

Freud, S. 1989. Totem and Taboo. London, WW Norton, 59.

Goryaeva, T.M. 1998. Censorship anatomy. New milestones, 2, 89-107.

Hayek, F.A. 2001. Road to Slavery. Moscow, 41.

Knyshenko, Yu.V. 1973. History of Primitive Society. Rostov-on-Don, 13.

Lotman, Yu.M. 2000. Semiosphere. St Petersburg, 704.

Lotman, Yu.M. 2002. Articles on Art Semiotics. St Petersburg, 144-145.

McSweeney, B. 2002. Hofstede's model of national cultural differences and their consequences: A triumph of faith a failure of analysis. Human Relations, 1(55), 89.

Plato. 1994. The State. Moscow, 654.

Plato. 1999. Laws. Moscow, 831.

Radcliffe-Brown, A.R. 2014. Taboo: The Frazer Lecture 1939. Cambridge University Press.

Severina, E.M., Agapova, S.G., Milkevich, E.S., Agapova, E.A. 2018. The Culture as a Cultural Concept within the Cognitive Context. The International Journal of Interdisciplinary Cultural Studies, 1(13), 15-28. 